\title{
Mobile Application for Self-Management in Schizophrenia: A Pilot Study
}

Raquel Simões de Almeida, Ana Couto, António Marques, Cristina Queirós \& Constantino Martins

To cite this article: Raquel Simões de Almeida, Ana Couto, António Marques, Cristina Queirós \& Constantino Martins (2018) Mobile Application for Self-Management in Schizophrenia: A Pilot Study, Journal of Technology in Human Services, 36:4, 179-190, DOI: 10.1080/15228835.2018.1483859

To link to this article: https://doi.org/10.1080/15228835.2018.1483859

曲 Published online: 31 Jul 2018.

Submit your article to this journal 저

山ll Article views: 303

Q View related articles ¿ك

View Crossmark data ־ 


\title{
Mobile Application for Self-Management in Schizophrenia: A Pilot Study
}

\author{
Raquel Simões de Almeida ${ }^{a, b}$, Ana Couto ${ }^{b}$, António Marques ${ }^{b}$, \\ Cristina Queirós ${ }^{a}$, and Constantino Martins ${ }^{c}$

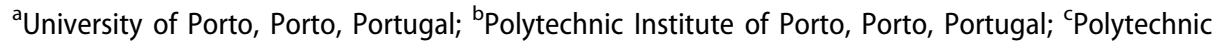 \\ Institute of Porto, Porto, Portugal
}

\begin{abstract}
There is an urgent need to develop more effective interventions for psychotic disorders. Mobile Health solutions can address this emerging problem but needs more research. This study aims to present a new intervention and have some preliminary data about weCOPE. The sample is constituted by nine participants with a mean age of 38 years $( \pm 9.701)$, being $78 \%$ men, and with mean clinical follow-up time of 10 years. The intervention lasted eightweeks and was followed by each user's case manager. The data collection was carried out in two moments (before and after the application use), using six evaluation instruments: Recovery Assessment Scale, Empowerment Scale, General Self-Efficacy Scale, Social Support Satisfaction Scale, Personal and Social Performance Scale, and Positive and Negative Syndrome Scale. The data collected through these instruments were analyzed later through descriptive and inferential statistics. The majority of the results were significant and indicate that weCOPE may produce an improvement in symptoms (general psychopathology), empowerment, recovery, satisfaction with social support, self-efficacy, and personal and social functioning. Thus, this kind of mobile technologies for schizophrenia selfmanagement may contribute to a subjective perception of the patient's better well-being and health condition.
\end{abstract}

\section{ARTICLE HISTORY}

Received 16 October 2017

Accepted 30 May 2018

\section{KEYWORDS}

Impact of technology;

mobile application; schizophrenia; selfmanagement; mHealth

\section{Introduction}

Schizophrenia is the most disabling mental illness and the costs of mental health services and burden are high compared to other diseases (Mueser \& McGurk, 2004; Tandon, Keshava, \& Nasrallah, 2008), due to its chronic and incapacitating course (Ganesh \& Gupta, 2017; Mueser \& McGurk, 2004; Owen, Sawa, \& Mortensen, 2016). Unfortunately, mental health care is still insufficient to address the needs of people with schizophrenia (Berry 
\& Haddock, 2008; Drake, Bond, \& Essock, 2009; Gulliver, Griffiths, \& Christensen, 2010; Mojtabai et al., 2009).

In the last years, there has been growing awareness about illness selfmanagement which plays an important role in empowering patients with chronic conditions, like schizophrenia, to manage their symptoms and to promote their recovery (Schie et al., 2016). Literature offers different general definitions of self-management regarding schizophrenia, although the definitions agree on the core elements (Schie et al., 2016), which are, according to WHO - Regional Office for Europe (2010, p. 2): "problem solving, goal setting, identifying triggers and indicators of deteriorating health and responding to these themselves before relying on clinician-led intervention." Thus, illness self-management can be defined as:

One approach that was designed to engage individuals with schizophrenia as active agents in their own treatment by teaching them to self-monitor their ongoing clinical status, avoid high-risk stressors, stay on track with their medications, and use various coping and compensatory strategies when symptoms and other problems associated with their psychiatric condition emerge. (Ben-Zeev et al., 2013, p. 2)

Additionally, there is strong evidence supporting the use and upcoming development of technologies to increase the accessibility and utilization of high-quality illness-management strategies for schizophrenia (AlvarezJimenez et al., 2014; Berry, Lobban, Emsley, \& Bucci, 2016; Ben-Zeev et al., 2015; Gire et al., 2017; Välimäki, Athanasopoulou, Lahti, \& Adams, 2016).

Mobile Health (mHealth) emerges as one of these technologies, being conducted on "mobile phones, patient monitoring devices, personal digital assistants and other wireless devices" (WHO - Global Observatory for eHealth, 2011, p. 6), and being a promising approach to delivery mental health care (Chan, Torous, Hinton, \& Yellowlees, 2014; Luxton, McCann, Bush, Mishkind, \& Reger, 2011). In fact, smartphones have proven increasingly feasible for controlling positive symptoms, preventing hospitalizations, increasing social interactions, reducing depression, and promoting adherence to medication (Ben-Zeev et al., 2014; Palmier-Claus et al., 2013; Sandoval, Torous, \& Keshavan, 2017). Moreover, there is a relatively high acceptability of online and smartphone interventions for mental illness (Berry et al., 2016: Niendam et al., 2018).

Because there is an imperative need to increase access to effective interventions for psychosis and the effectivity of mHealth, and among these patients it is not very clear, we develop a mobile application, weCOPE, as a therapeutic intervention to illness self-management. This app (application) was developed to address the treatment gap and reduce the costs of selfmanagement interventions, and was designed by engineers and mental health professionals, including four modules (which were previously chosen by users and professionals in the stages further described in Methods): 
symptom monitoring, problem-solving, anxiety management, and goal setting, allowing also the contact with therapists in crisis situations. These modules were identified as priorities in illness self-management and were chosen by future users (people with schizophrenia and also professionals).

This study aims to present the acceptability and model of analysis of weCOPE app.

\section{Methods}

This study is quantitative pre-experimental research employing pretest and posttest design. However, before we present the results of this pilot study, it is important to present the process of the app development.

\section{weCOPE development}

To develop the weCOPE app, a research was conducted with users and practitioners at a community-based rehabilitation service, considering three stages. On Stage 1 we used a sample of 102 individuals with schizophrenia, who completed an online survey reporting on their current use of mobile devices and interest in mHealth services. Six practitioners participated in a focus group examining their attitudes and expectations from a mHealth intervention, and identified needs and potential obstacles. On Stage 2, a multidisciplinary team incorporated these inputs and designed the app. Finally, on Stage 3, the prototype was tested by six users and six professionals, who performed several tasks and provided "think aloud" commentary and postsession usability ratings.

The final prototype was composed by the following four modules: the symptom monitoring module shares one of the goals of Cognitive Behavioral Therapy (including modifying patients' distorted beliefs about delusions and hallucinations), and having as its main objective to monitor the frequency, intensity, and duration of psychotic symptoms, their triggering events, and the conditions that maintain them; the problem-solving module aims to identify and modify the maladaptive strategies to develop more helpful alternatives, and the user must identify the problem and describe it, presenting two possible solutions and selecting his preferred one; the anxiety-management module purposes the reduction of factors such as stress for a better control of the pathology and its symptoms, where the user can explore different types of relaxation, such imagery, with the option of male or female voice, like he feels more comfortable; finally, in goal-setting module the user has to define the goal, the times that he will make some progress to achieve them and the support that he will require, so he can have an attitude of empowerment in their recovery. 
The use of the app was free, based on the need of each user, and the usage data was guaranteed through an algorithm created that registers them on the server and allows to be consulted. It should be noted that if the medication of any of the participants changed, the case manager would be responsible for communicating that to the researcher. At this moment, we performed a pilot study to assess the acceptability and model of analysis of weCOPE app.

\section{Participants}

The sample consists of a group of 9 participants from Associação Nova Aurora (ANARP), an outpatient community rehabilitation center in Portugal that provides mental health services to support and help people with mental health problems to gain or regain skills and confidence to live as independently as possible. A convenience sampling was chosen, considering that participants were from ANARP and volunteered to participate in the study.

According to the study's aims, inclusion criteria are: adults over 18 years, diagnosis of schizophrenia, attend psychosocial rehabilitation services, access to a mobile device compatible with the application, and voluntary acceptance to participate. The exclusion criteria are: clinical instability; lack of basic skills in the use of information and communication technologies; and having associated cognitive deficits, that is, obtain the minimum score of 26 in the Mini Mental State Examination (previously administered by the institution). ANARP has 43 users, among 21 people with schizophrenia who fit the criteria, 10 people were willing to participate in this pilot study, but one of them was discharged during the study.

\section{Instruments}

To assess the variables mentioned previously, the following instruments were selected:

- Recovery Assessment Scale (Corrigan et al., 2004; validated for Portuguese population by Sousa et al., 2009), a self-report scale with 24 items quoted on a 5-point Likert scale, meaning the higher the score the better recovery result. This scale comprehends five dimensions: personal confidence and hope, willingness to ask for help, goal and success orientation, reliance on others, and nondomination by symptoms.

- Empowerment Scale (Rogers et al., 1997; validated for Portuguese population by Almeida \& Pais-Ribeiro, 2011) to assess subjective feelings of empowerment, being a self-completion scale of 28 items quoted 
on a 4-point Likert scale, where a high score means a better result of empowerment. This scale comprehends five dimensions: esteem and efficacy, power and powerlessness, optimism and control over the future, community activism and autonomy, and righteous anger.

- General Self-Efficacy Scale (Pais-Ribeiro, 1995, adapted to Portugal based on the original Self-Efficacy Scale from Sherer et al., 1982), a selfcompletion scale of 15 items quoted on a 7-point Likert scale, evaluating the subjective perception of personal effectiveness of the user to deal adequately with a wide range of situations. A high result means a more positive subject's perception. This scale comprehends three dimensions: initiation and persistence, efficacy in adversity, and social efficacy.

- Social Support Satisfaction Scale (Pais-Ribeiro, 1999), a self-completion scale of 15 items, where the participant should indicate the degree of agreement with the affirmation, in a Likert scale with 5 points, and a high score means high satisfaction. This scale comprehends four dimensions: satisfaction with friendship, intimacy, satisfaction with family, and social activities.

- Personal and Social Performance Scale (Morosini et al., 2000; validated for Portuguese population by Brissos et al., 2012), that assesses social functioning in four domains (socially useful activities, personal and social relationships, self-care, and disturbing and aggressive behavior), and a high overall score means a better social and personal functioning.

- Positive and Negative Syndromes Scale (Kay, Fiszbein, \& Qpler, 1987; translated for Portuguese by Vessoni, 1993), that evaluates symptomatology in schizophrenia. This scale is fulfilled by the evaluator after a specific interview, and consists of 30 items quoted on a 7-point Likert scale, where a high score means a severe symptomatology.

\section{Procedure}

To collect data, this research project was submitted to the institution board ethic committee of the institution, and after being approved, the participants were contacted. A prototype version of the weCOPE app was presented to participants and they were recruited through their availability. After the study was described, informed consent was sought and the participants subsequently participated in a short demonstration of how to use the app. Researchers ensure that they are not obliged to participate in the research, regardless of their attendance in ANARP and there are no consequences for refusing to take part. Recovery Assessment Scale, Empowerment Scale, General Self-Efficacy Scale, Personal and Social Performance Scale, Positive and Negative Syndromes Scale, and Social Support Satisfaction Scale were applied by an independent researcher in a 
neutral environment, while another researcher gathers the demographics data. Initially, the therapist introduced the mHealth intervention to patients and explained how to use the mobile application (e.g., login). Next, each participant used the application during 8 weeks under the supervision of their case manager and in the last phase, the final evaluation was applied by the same evaluators in the same environment, in order to collect data to verify the impact of the intervention provided.

\section{Data analyses}

Statistical data analyses were performed using IBM Statistical Package for the Social Sciences version 24, namely descriptive statistics with nominal variables being categorized by absolute (n) and relative (\%) frequencies, and quantitative variables by central (mean) and dispersion measures (standard deviation). A significance level of 0.05 was considered, and t-tests were planned for paired samples, and it was intended to compare the means of pretest with the posttest results. The normality assumption was not verified with Shapiro-Wilk test, since the sample size is less than 30, which implies to use nonparametric Wilcoxon test to compare paired samples. Because we performed multiple comparisons there is a high chance of type I error in this study, implying that these findings should be considered preliminary and obtained in a pilot study, needing to have further replication.

\section{Results}

Participants presented a mean age of $\approx 38.11$ years $( \pm 9.701)$ and a mean of $\approx 9.78$ years $( \pm 5,403)$ being clinically followed in ANARP (Table 1). Seventy eight percent were men, $89 \%$ single, and $11 \%$ divorced. All of them were Caucasian and from middle/low socioeconomic class. Considering education level, $44 \%$ presented elementary education, $44 \%$ secondary education, and $11 \%$ higher education; $89 \%$ were unemployed and $11 \%$ retired which $22 \%$ did not present any type of income source, $11 \%$ received Social Security Income (SSI), and 67\% received Social Security Disability Insurance (SSDI). Regarding family unit, $44 \%$ presented simple household (single-parent), 33\% simple household (nuclear), $11 \%$ an aggregate without familiar nucleus, and $11 \%$ a complex household. The participants were to use the app whenever they felt the need to. The majority of participants (45\%) used the app two or three times a week. All participants described themselves as experienced with technology.

Regarding the results of the scales (Table 2), in the Recovery Assessment Scale there were statistically significant values only in the subscales 
Table 1. Characterization of the sample $(n=9)$.

\begin{tabular}{llccc}
\hline Variables & \multicolumn{1}{c}{ Minimum } & Maximum & Mean & Standard Deviation \\
\hline Age & 27 & 54 & 38.11 & \pm 9.701 \\
Number of years of accompaniment & 2 & 21 & 9.78 & \pm 5.403 \\
Variables & Female & $n$ & $\%$ \\
Gender & Male & 2 & 22.2 \\
\multirow{2}{*}{ Marital status } & Divorced & 7 & 77.8 \\
& Single & 1 & 11.1 \\
Level of education & Elementary education & 8 & 88.9 \\
& Secondary education & 4 & 44.4 \\
\multirow{3}{*}{ Work situation } & Higher education & 4 & 44.4 \\
\multirow{3}{*}{ Income source } & Unemployed & 1 & 11.1 \\
& Retired & 8 & 88.9 \\
Family unit & None & 1 & 11.1 \\
& SSI & 2 & 22.2 \\
& SSDI & 1 & 11.1 \\
& Simple household (single-parent) & 6 & 66.6 \\
& Simple household (nuclear) & 4 & 44.4 \\
& Aggregate without familiar nucleus & 3 & 33.3 \\
& Complex household & 1 & 11.1 \\
\end{tabular}

Note. SSI = Social Security Income; SSDI = Social Security Disability Insurance.

"personal confidence and hope," "goals and success orientation," and "life beyond symptoms," with the mean score increasing in all subscales, with a higher score meaning a better recovery result. The total score also presented significant results and the mean also increased. The Empowerment Scale revealed statistically significant values only in the subscales "esteem and efficacy," "optimism over future," and "righteous anger," and the mean increased in all subscales. The total score of the scale also presented significant results and the mean also increased. The Social Support Satisfaction Scale presented statistically significant values only in subscales "intimacy" and "satisfaction with family," and regarding the mean, it increased in all subscales, excepting the subscale "social activities." The General SelfEfficacy Scale showed statistically significant values only in subscales "initiation and persistence" and "effectiveness in adversity," and the mean increased in all subscales, excepting subscale effectiveness in adversity. The total score of the scale also presented significant results and the mean also increased. Regarding the Positive and Negative Syndromes Scale, we found statistically significant values only in the general psychopathology subscale, and the mean decreased in all subscales. The total score of the scales did not present significant results, but the mean also decreased. Finally, in Personal and Social Performance we found significant results on the total score of the scale and the mean also increased, with a higher score meaning a better result. The results showed improvements for each subject in the means of all scales with an increase in all of them (improvement in perception of recovery, self-esteem, social support, empowerment, and performance) and a decrease in the PANSS scale (symptom reduction). 
Table 2. Means comparison results of preassessment and postassessment.

\begin{tabular}{|c|c|c|c|c|}
\hline Scale & Subscale & Pretest $( \pm S P)$ & Posttest $( \pm \mathrm{SP})$ & $p$ Wilcoxon \\
\hline Recovery & Personal confidence and hope & $32.56( \pm 5.053)$ & $38.89( \pm 3.257)$ & $0.011^{*}$ \\
\hline \multirow[t]{4}{*}{ Assessment Scale } & Willingness to ask for help & $11.44( \pm 1.944)$ & $13.11( \pm 1.167)$ & 0.065 \\
\hline & Orientation for goals and for success & $19.89( \pm 2.088)$ & $22.22( \pm 2.108)$ & $0.033^{*}$ \\
\hline & Confidence in others & $16.00( \pm 1.323)$ & $17.11( \pm 1.269)$ & 0.168 \\
\hline & Nondomination by symptoms & $10.00( \pm 2.291)$ & $12.78( \pm 1.481)$ & $0.033^{*}$ \\
\hline Total & & $89.89( \pm 9.253)$ & $104.11( \pm 7.407)$ & $0.008^{* *}$ \\
\hline \multirow[t]{5}{*}{ Empowerment Scale } & Self-esteem and self-confidence & $24.56( \pm 3.321)$ & $29.44( \pm 3.046)$ & $0.017^{*}$ \\
\hline & Current power & $18.89( \pm 3.100)$ & $19.56( \pm 4.756)$ & 0.483 \\
\hline & Community activism & $17.89( \pm 1.833)$ & $19.78( \pm 2.438)$ & 0.062 \\
\hline & Optimism & $9.78( \pm 1.481)$ & $12.56( \pm 1.333)$ & $0.011^{*}$ \\
\hline & Wrath & $8.44( \pm 1.509)$ & $10.25( \pm 2.188)$ & 0.034 \\
\hline Total & & $71.22( \pm 6.379)$ & $82.11( \pm 5.840)$ & $0.017^{*}$ \\
\hline Social Support & Satisfaction with friends & $16.29( \pm 3.111)$ & $17.57( \pm 2.284)$ & 0.234 \\
\hline \multirow[t]{3}{*}{ Satisfaction Scale } & Intimacy & $13.86( \pm 1.452)$ & $16.29( \pm 1.637)$ & $0.012^{*}$ \\
\hline & Satisfaction with family & $11.29( \pm 1.918)$ & $13.00( \pm 1.323)$ & $0.026^{*}$ \\
\hline & Social activities & $9.71( \pm 1.982)$ & $9.571( \pm 0.681)$ & 0.634 \\
\hline Total & & $50.86( \pm 6.936)$ & $56.43( \pm 3.737)$ & $0.021^{*}$ \\
\hline General Self- & Initiation and persistence & $22.57( \pm 4.268)$ & $31.43( \pm 3.964)$ & $0.008^{* *}$ \\
\hline \multirow[t]{2}{*}{ Efficacy Scale } & Effectiveness in adversity & $19.71( \pm 3.151)$ & $16.71( \pm 2.044)$ & $0.011^{*}$ \\
\hline & Social effectiveness & $14.71( \pm 2.816)$ & $27.86( \pm 4.512)$ & 0.258 \\
\hline Total & & $57.00( \pm 5.523)$ & $76.00( \pm 9.000)$ & $0.007^{* *}$ \\
\hline Positive and Negative & Positive symptoms & $10.56( \pm 3.812)$ & $9.78( \pm 2.438)$ & 0.180 \\
\hline \multirow[t]{2}{*}{ Syndromes Scale } & Negative symptoms & $11.22( \pm 3.492)$ & $11.00( \pm 3.162)$ & 0.655 \\
\hline & General psychopathology & $25.44( \pm 8.293)$ & $22.67( \pm 6.782)$ & $0.027^{*}$ \\
\hline Total & & $47.22( \pm 12.76)$ & $43.44( \pm 9.342)$ & 0.062 \\
\hline $\begin{array}{l}\text { Personal and Social } \\
\text { Performance Scale }\end{array}$ & $61.89( \pm 15.112)$ & \multicolumn{2}{|c|}{$74.78( \pm 8.772)$} & $0.012^{*}$ \\
\hline
\end{tabular}

${ }^{*} p<0.05$ means the value is statistically significant.

\section{Discussion and conclusions}

The implementation of more technological approaches, complementary to the mental health and psychiatric services provided, has the potential to change the way some interventions are delivered and, thereby, promote recovery and patient choice and reduce the illness costs. Evidence for feasibility and acceptability of mobile technologies for people with schizophrenia is important and it is necessary to identify new strategies and tools for promoting illness self-management, engagement in services, self-monitoring, and treatment programs, allowing to extend mental health care to more patients.

We developed and proposed the use of a mobile phone app, weCOPE, as a way to assist illness self-management in people with schizophrenia. Based on previous studies and the initial study results presented, it is reasonable to speculate that the app may benefit people from the target population. In fact, regarding scales' results, in Recovery Assessment Scale the total score was statistically significant, and we found statistically significant values in the subscales "personal confidence and hope," "goals and success orientation," and "nondomination by symptoms," despite the means increased in all dimensions. It should be noted that on the subscale "willingness to ask for help" the mean increased, although the values were not statistically significant, which is supported by a study (Stafford et al., 2015), where 
participants mention that the use of web-based eHealth program for young people with psychotic-like experiences encourages appropriate help seeking when required.

In the Empowerment Scale, statistically significant values were found in the total score and in the subscales "esteem and confidence," "optimism," and "righteous anger." It should also be noted that although only significant values were found in this subscales, all the means increased. Technologies can effectively take on the role of empowering people with mental health problems (Calvillo, Román, \& Roa, 2015).

In the Social Support Satisfaction Scale we found statistically significant values in the total score, and regarding means, it increased in all subscales, with the exception of subscale "social activities" which can be justified by the fact that the use of new technologies can lead to social isolation (Jenaro, Flores, Gómez-vela, González-Gil, \& Caballo, 2007).

In the General Self-Efficacy Scale, the total score of the scale presented significant results which may suggest that the use of weCOPE increases the perception of self-efficacy. This is corroborated by Mueser and colleagues (2002), who mention that many programs of self-management go beyond the traditional approach with focus on psychopathology, and strive to improve self-efficacy and to foster skills that help people pursue their personal goals. Regarding the subscales, we found statistically significant values only in subscales "initiation and persistence" and "effectiveness in adversity."

Considering the Positive and Negative Syndromes Scale, in our results the mean of the subscales and the total value of the test decreased with the use of the weCOPE app, which suggests, according to this scale, that the lower the score, the lower the symptomatology. These results are also verified in other researches, such as done by Ben-Zeev and colleagues (2014), who studied the feasibility, acceptability, and preliminary efficacy of FOCUS, a smartphone system designed to support self-management of illness in individuals with schizophrenia. However, in their study the results were statistically significant in the total score scale, in the "positive symptoms" and "general psychopathology" subscales, while in our study we found only significant results in the general psychopathology subscale, suggesting that the weCOPE app could effectively help to manage and reduce the symptoms of general psychopathology in this population.

Finally, in the Personal and Social Performance scale we found significant results on the total score, which included socially useful activities (namely work and study), personal and social relationships, self-care, and disturbing and aggressive behaviors. However, we have a clear perception that this result is greatly affected by all the psychosocial interventions that these patients receive concomitantly. 
This work is a first preliminary step to test this innovative intervention, suggesting that this pilot study should be regarded with cautions due to its limitations: sample and convenience size, lack of control group, or adjustment for symptoms severity and demographics. Thus, symptomology and other analyses will be explored in the future using a bigger sample. Overall, the results show that weCOPE is a potentially valuable tool to support illness self-management in schizophrenia accordingly to recovery concept's measures.

To conclude, the main accomplishment of this study is to present a new technological tool-a mobile app-to help people with schizophrenia manage their illness. Despite the positive preliminary results of this pilot study, future research is needed to evaluate this tool in more rigorously controlled studies, with larger samples and to examine whether symptom improvements and recovery gains persist over time. In our opinion, improving usability, adding human/professional support, and adding more interactive elements could boost patient engagement. Then, given the barriers associated to the access of psychosocial interventions (Thompson, Gleeson, \& Alvarez-Jimenez, 2018), mHealth can offer an opportunity without precedents to improve the state and quality of health of people with schizophrenia.

\section{References}

Almeida, M., \& Pais-Ribeiro, J. (2011). Empowerment em adultos da comunidade. Porto: UNIESEP, Núcleo de investigação em Saúde e Qualidade de Vida.

Alvarez-Jimenez, M., Alcazar-Corcoles, M. A., González-Blanch, C., Bendall, S., McGorry, P. D., \& Gleeson, F. (2014). Online, social media and mobile technologies for psychosis treatment: A systematic review on novel user-led interventions. Schizophrenia Research, 156, 96-106.

Ben-Zeev, D., Brenner, C., Begale, M., Duffecy, J., Mohr, D., \& Mueser, K. (2014). Feasibility, acceptability, and preliminary efficacy of a smartphone intervention for schizophrenia. Schizophrenia Bulletin, 40, 1244-1253.

Ben-Zeev, D., Kaiser, S. M., Brenner, C. J., Begale, M., Duffecy, J., \& Mohr, D. C. (2013). Development and usability testing of FOCUS: A smartphone system for self-management of schizophrenia. Psychiatric Rehabilitation Journal, 36, 289-296. doi:10.1037/prj0000019

Ben-Zeev, D., Schueller, S., Begale, M., Duffecy, J., Kane, J., \& Mohr, D. (2015). Strategies for mHealth research: Lessons from 3 mobile intervention studies. Administration and Policy in Mental Health and Mental Health Services Research, 42, 157-167. doi:10.1007/ s10488-014-0556-2

Berry, K., \& Haddock, G. (2008). The implementation of the NICE guidelines for schizophrenia: Barriers to the implementation of psychological interventions and recommendations for the future. Journal of Psychology and Psychotherapy: Theory, Research and Practice, 81, 419-436. doi:10.1348/147608308X329540

Berry, N., Lobban, F., Emsley, R., \& Bucci, S. (2016). Acceptability of interventions delivered online and through mobile phones for people who experience severe mental 
health problems: A systematic review. Journal of Medical Internet Research, 18, e121. doi:10.2196/jmir.5250

Brissos, S., Palhavã, F., Marques, J. G., Mexia, S., Carmo, A. L., Carvalho, M., ... Figueira, M. L. (2012). The Portuguese version of the personal and social performance scale (PSP): Reliability, validity, and relationship with cognitive measures in hospitalized and community schizophrenia patients. Social Psychiatry Psychiatric Epidemiology, 47, 1077-1086. doi:10.1007/s00127-011-0412-6

Calvillo, J., Román, I., \& Roa, L. M. (2015). How technology is empowering patients? A literature review. Health Expectations, 18, 643-652. doi:10.1111/hex.12089

Chan, S., Torous, J., Hinton, L., \& Yellowlees, P. (2014). Mobile tele-mental health: Increasing applications and a move to hybrid models of care. Healthcare, 2, 220-233. doi:10.3390/healthcare2020220

Corrigan, P., Salzer, M., Ralph, R., Sangster, Y., \& Keck, L. (2004). Examining the factor structure of recovery assessment scale. Schizophrenia Bulletin, 30, 1035-1041.

Drake, R., Bond, G., \& Essock, S. (2009). Implementing evidence based practices for people with schizophrenia. Schizophrenia Bulletin, 35, 704-713. doi:10.1093/schbul/ $\operatorname{sbp} 041$

Ganesh, K., \& Gupta, S. (2017). Comparison of unmet needs of patients on treatment of schizophrenia perceived by patients and their family caregivers. Indian Journal of Social Psychiatry, 33, 181-186. doi:10.4103/ijsp.ijsp_31_16

Gire, N., Farooq, S., Naeem, F., Duxbury, J., McKeown, M., Kundi, P. S., ... Husain, N. (2017). mHealth based interventions for the assessment and treatment of psychotic disorders: A systematic review. mHealth, 3, 33. doi:10.21037/mhealth. 2017.07.03

Gulliver, A., Griffiths, K., \& Christensen, H. (2010). Perceived barriers and facilitators to mental health help-seeking in young people: A systematic review. BMC Psychiatry, 10, 113-121. doi:10.1186/1471-244X-10-113

Jenaro, C., Flores, N., Gómez-Vela, M., González-Gil, F., \& Caballo, C. (2007). Problematic internet and cell-phone use: Psychological, behavioral, and health correlates. Addiction Research and Theory, 15, 309-320.

Kay, S. R., Fiszbein, A., \& Opler, L. A. (1987). The positive and negative syndrome scale (PANSS) for schizophrenia. Schizophrenia Bulletin, 13, 261-278.

Luxton, D., McCann, R., Bush, N., Mishkind, M., \& Reger, G. (2011). mHealth for mental health: Integrating smartphone technology in behavioral healthcare. Professional Psychology, Research and Practice, 42, 505-512. doi:10.1037/a0024485

Mojtabai, R., Fochtmann, L., Chang, S. W., Kotov, R., Craig, T. J., \& Bromet, E. (2009). Unmet need for mental health care in schizophrenia: An overview of literature and new data from a first admission study. Schizophrenia Bulletin, 35, 679-695. doi:10.1093/ schbul/sbp045

Morosini, P., Magliano, L., Brambilla, L., Ugolini, S., \& Pioli, R. (2000). Development, reliability and acceptability of a new version of the DSM-IV social and occupational functioning assessment scale: (SOFAS) to assess routine social functioning. Acta Psychiatrica Scandinavica, 101, 323-329.

Mueser, K., Corrigan, P., Hilton, D., Tanzman, B., Schaub, A., Gingerich, S., ... Herz, M. (2002). Illness management and recovery: A review of the research. Psychiatric Services, $53,1272-1284$.

Mueser, K., \& McGurk, S. (2004). Schizophrenia. The Lancet, 363, 2063-2072.

Niendam, A., Tully, L., Iosif, A., Kumar, D., Nye, K., Denton, J., ... Pierce, K. (2018). Enhancing early psychosis treatment using smartphone technology: A longitudinal feasibility and validity study. Journal of Psychiatric Research, 96, 239-246. 
Owen, M., Sawa, A., \& Mortensen, P. (2016). Schizophrenia. The Lancet, 388, 86-97. doi:10.1016/S0140-6736(15)01121-6

Pais-Ribeiro, J. (1995). Avaliação de uma escala de autoeficácia geral. In L. S. Almeida \& I. S. Ribeiro (Orgs), Avaliação Psicológica: Formas e Contextos. Braga: APPORT.

Pais-Ribeiro, J. (1999). Escala de satisfação com o suporte social (ESSS). Análise Psicológica, 3, 547-558.

Palmier-Claus, J., Rogers, A., Ainsworth, J., Machin, M., Barrowclough, C., Laverty, L., ... Lewis, S. (2013). Integrating mobile-phone based assessment for psychosis into people's everyday lives and clinical care: A qualitative study. BMC Psychiatry, 13, 34. doi:10.1186/1471-244X-13-34

Rogers, E., Chamberlin, J., Ellison, M., \& Crean, T. (1997). A consumer-constructed scale to measure empowerment among users of mental health. Psychiatric Services, 48, 1042-1047.

Sandoval, L., Torous, J., \& Keshavan, M. (2017). Smartphones for smarter care? Selfmanagement in schizophrenia. The American Journal of Psychiatry, 174, 725-728.

Schie, D., Castelein, S., van der Bijl, J., Meijburg, R., Stringer, B., \& van Meijel, B. (2016). Systematic review of self-management in patients with schizophrenia: Psychometric assessment of tools, levels of self-management and associated factors. Journal of Advanced Nursing, 72, 2598-2611. doi:10.1111/jan.13023

Sherer, M., Maddux, J. E., Mercandante, B., Prentice-Dunn, S., Jacobs, B., \& Rogers, R. W. (1982). The self-efficacy scale: Construction and validation. Psychological Reports, 51, 663-671. doi:10.2466/pr0.1982.51.2.663

Sousa, S., Oliveira, S., Marques, A., Pereira, E. G., \& Queirós, C. (2009). Autoestigma e potencial de recovery na Esquizofrenia. Poster no VI Colóquio Internacional de Esquizofrenia do Porto, 19-20 Junho, Porto.

Stafford, E., Hides, L., \& Kavanagh, D. (2015). The acceptability, usability and short-term outcomes of Get Real: A web-based program for psychotic-like experiences (PLEs). Internet Interventions, 2, 266-271.

Tandon, R., Keshava, M., \& Nasrallah, H. (2008). Schizophrenia, "Just the Facts": What we know in 2008. Part 1: Overview. Schizophrenia Research, 100, 4-19.

Thompson, A., Gleeson, J., \& Alvarez-Jimenez, M. (2018). Should we be using digital technologies in the treatment of psychotic disorders? Australian \& New Zealand Journal of Psychiatry, 52, 225. doi:10.1177/0004867418757920

Välimäki, M., Athanasopoulou, C., Lahti, M., \& Adams, C. E. (2016). Effectiveness of social media interventions for people with schizophrenia: A systematic review and metaanalysis. Journal of Medical Internet Research, 18, e92. doi:10.2196/jmir.5385

Vessoni, A. (1993). Adaptação e estudo da confiabilidade da Escala de Avaliação das Sindromes Positiva e Negativa para a esquizofrenia no Brasil. (Master's thesis). Universidade Federal de São Paulo, São Paulo, Brasil.

WHO - Global Observatory for eHealth (2011). mHealth new horizons for health through mobile technologies. World Health Organization: Geneva, Switzerland.

WHO - Regional Office for Europe. (2010). Empowerment in mental health - Working together towards leadership: Self-management of mental health problems. Leuven, Belgium: World Health Organization. 